\title{
Communication \\ UALGORITMO, a New Instrument of the University of Algarve for Scientific Outreach
}

\author{
José Bragança ${ }^{1,2,3, *(D)}$, Sónia Figueiredo ${ }^{4}$, Carla Alexandra Rego ${ }^{5}$, Filomena dos Reis Conceição ${ }^{6}$ \\ and Saúl Neves de Jesus ${ }^{7,8}$
}

1 Faculdade de Medicina e Ciências Biomédicas (FMCB), Universidade do Algarve, Campus de Gambelas, 8005-139 Faro, Portugal

2 Algarve Biomedical Center Research Institute, ABC-RI, 8005-139 Faro, Portugal

3 Champalimaud Research Program, Champalimaud Center for the Unknown, 1400-038 Lisbon, Portugal

4 School José Belchior Viegas, Sítio da Calçada, 8150-021 São Brás de Alportel, Portugal; sonia.figueiredo@aejbv.pt

5 Schools Pinheiro e Rosa, 8005-546 Faro, Portugal; carego@aeprosa.pt

6 High School Tomás Cabreira, 8000-075 Faro, Portugal; filomena.conceicao@agr-tc.pt

7 Faculdade de Ciências Humanas e Sociais, Universidade do Algarve, 8005-139 Faro, Portugal; snjesus@ualg.pt

8 Centro de Investigação em Turismo, Sustentabilidade e Bem-estar (CinTurs), Universidade do Algarve, Campus de Gambelas, 8005-139 Faro, Portugal

* Correspondence: jebraganca@ualg.pt

check for updates

Citation: Bragança, J.; Figueiredo, S.; Rego, C.A.; dos Reis Conceição, F.; Neves de Jesus, S. UALGORITMO, a New Instrument of the University of Algarve for Scientific Outreach. BioChem 2022, 2, 93-103. https:// doi.org/10.3390/biochem2010007

Academic Editors: Manuel Aureliano, M. Leonor Cancela, Célia M. Antunes and Ana Rodrigues Costa

Received: 20 December 2021

Accepted: 24 February 2022

Published: 3 March 2022

Publisher's Note: MDPI stays neutral with regard to jurisdictional claims in published maps and institutional affiliations.

Copyright: (C) 2022 by the authors. Licensee MDPI, Basel, Switzerland. This article is an open access article distributed under the terms and conditions of the Creative Commons Attribution (CC BY) license (https:// creativecommons.org/licenses/by/ $4.0 /)$.

\begin{abstract}
Researchers at Universities generate and convey the knowledge acquired through communications in specialized (inter)national journals and congresses. An effort to share the scientific achievements with the general public is extremely important. For this purpose, we have launched the UALGORITMO, a journal freely accessible online, written in lay Portuguese language by Researchers of the University of the Algarve, to summarize recent communications published in peer reviewed journals. After submission, the manuscripts are revised by High Schools Students of the Algarve, under the guidance of a schoolteacher, for further simplification of the language and general improvement of the manuscript and figures. The revised manuscripts by the authors are edited and published, with an acknowledgment and a presentation of the reviewers at the end of each article. To maximize the outreach, the articles include a summarized biography of the authors, and links to their research centers and teaching courses. We believe that the UALGORITMO is a valuable instrument to promote scientific literacy and culture amongst all communities.
\end{abstract}

Keywords: outreach; layman; high school education; public engagement; science communication; scientific literacy

\section{Introduction}

Universities have as their principal mission to generate and share knowledge, but these institutions also have to contribute to the education of all surrounding communities. Thus, the scientific dissemination and communication to the general public contributes to the latter vocation of the Universities, as it presents the value of the scientific production in simpler terms, as well as the potential benefits of these research activities for each individual in the society and for the society as a whole. In academia, most of the research activities are funded by governmental, charity, and/or philanthropic organizations, which strongly value the importance of the communication of the scientific results originated with their support, not only in renowned and specialized meetings and peer reviewed journals, but also through the direct engagement in public and lay outreach actions [1] Scientific outreach is also very important to convey scientific literacy to the public and may be considered as an educational tool that can be used across students' communities to enrich their curricular training, and to encourage them to engage in future scientific careers [2-4]. 
In fact, science communication is not only essential for sharing exciting new scientific achievements to the public, but also has an important role in providing knowledge, understanding and appreciation of science, both to the general public and non-scientist decision-makers, for taking better consensual decisions about individual and collective lives, health, and happiness [5]. Moreover, with the exponential scientific progress happening continuously in all research and engineering domains, for science communication to be efficient, scientists and other science conveyers have to communicate the right message obtained from the most reliable and accurate sources of information to the right audience with the most appropriate and accessible tools [3-6]. Bearing this idea in mind, in recent years, numerous scientific communication journals have been directed to a variety of readers, such as full-time researchers, to help them to keep up to date with all scientific publication of interest, science conveyers, teachers, and students of all ages, as well as families.

The strategies developed by scientists for public outreach are numerous, such as presentations of the research activities during open days at the institutions, lectures to lay public, interventions and interviews in traditional news media or novel social platform media, publications of books or videos for lay public, and through both institutional and personal websites. The strategies may also vary according to the scientists' age and status. Indeed, studies across several countries have indicated that older scientists are generally more incline to participate in outreach activities than younger colleagues [7]. Perhaps this situation is due to the fact that older scientists are likely to hold leadership positions with more time to spare for events that are beyond the scope of the research activities, while younger scientists are more focused and involved in working on their research projects and career progression. Moreover, older scientists prefer the presentations in traditional news media and books, while younger scientists would rather participate in events in direct contact with the public [1]. In any case, the most commonly reported obstacles by scientists for engaging in outreach events with the public are the lack of time necessary for these activities, the absence of specific funding, and no institutional incentive for these activities [8]. In addition, scientists often perceive themselves as poorly trained, and with little confidence in their communication skills, to efficiently participate in outreach activities and to exhilarate the public [3,7]. Interestingly, the most consistent factors to encourage scientists to take part in outreach activities are the conviction that they will enjoy the activity, be efficient in the transmission of their message and information to the public, and of course, have the time to engage in these activities [7].

The University of Algarve has a long-lasting track record of interactions and engagement with the public, in particular to primary and secondary schools of the Algarve through diversified initiatives. Indeed, the University of Algarve organizes free open days and site visits to the University, and summer classes for students and teachers of primary and secondary schools. Lectures and other activities jointly coordinated with schools, and adapted to the requests and needs of the school students and teachers, are also organized either at the University campuses or at the schools. The University of Algarve and its research centers have also obtained funding for the development of an Itinerant Mobile Molecular Genetics Laboratory (Lab-IT), which proposes hands-on practical laboratory sessions at secondary schools using basic molecular biology techniques. The Lab-It also promotes molecular genetics knowledge and disseminates applications of molecular biology in biomedical, pharmaceutical, forensic, biotechnological, and environmental sciences, amongst other domains. In addition, the University of Algarve collaborates closely with the Ciência Viva Center of the Algarve (http:/ / www.ccvalg.pt/, accessed on 15 December 2021), which was the first interactive Center of the Portuguese Ciência Viva Centers network, dedicated precisely to the dissemination of scientific and technological knowledge to lay public, in particular to the youth community. The Ciência Viva Center of the Algarve has a permanent exposition on local sea resources and wildlife, environment and green 
energy, and activities related to biology, physics, and chemistry, which are often closely involved with projects developed at the University of Algarve, with the participation of its researchers. Finally, researchers of the University of Algarve are frequently invited to share their new findings or to comment on novel scientific advances in mainstream and specialized national media. Here, we describe the UALGORITMO, a journal freely accessible online created as a novel outreach instrument of the University of Algarve.

\section{The UALGORITMO, a Collaboration between the University and Secondary High Schools}

The UALGORITMO was developed as an instrument to disseminate all recent research, technological, and art activities of the University of Algarve, using an approach previously unexplored that is complementary to the other outreach strategies already implemented at the University. The UALGORITMO is a journal that is freely accessible online and downloadable in a PDF format in several websites, such as https:/ / www.ualg.pt/en/ualgoritmo-magazine (accessed on 15 December 2021), https:/ / ualgoritmo.wixsite.com/website (accessed on 15 December 2021), amongst others. The UALGORITMO publishes concise communications in layman Portuguese language about the main results or activities previously described by researchers of the University of Algarve in mainstream indexed journals. Communications on any research topic are freely submitted via email by the authors to the editor of the UALGORITMO, who verifies that the main author of the work previously published in a mainstream journal is a researcher from the University of Algarve, and that the submitted communication only presents the results of the mainstream publication. Thus, the UALGORITMO contains review articles, formatted in a rather classical way, as many other magazines or journals with the same objective. Indeed, each article has a title, presents the authors and their affiliations, has an attractive graphical abstract designed to help the readers quickly gain an insight about the topic presented, a Portuguese abstract and its English version, an introduction, a section summarizing the results, and a conclusion to the communication. A reference to the original manuscript(s) serving as a base for the manuscript in the UALGORITMO, and previously evaluated and approved by expert researchers in peer-reviewed journals is also indicated.

As the communications published in the UALGORITMO are intended for lay public and not for expert scientists, the authors are instructed to submit a manuscript written in a very accessible language, using everyday terms. Noticeably, scientists are good at presenting their knowledge/work to their peers, but they fail or have more difficulties when it comes to communicating to a lay public [3,7]. Thus, to maximize the impact of this project, we implemented a revision process of the manuscripts submitted to the UALGORITMO by students (of the 10th to 12th year grade) from secondary high schools in the Algarve, under the coordination of at least one schoolteacher (Figure 1).

The role of the reviewers is to evaluate whether manuscripts under review are written clearly, and whether the message of the authors is understandable by them, who are a representative group of lay people. The reviewers are also asked to signal the sections in the text that are unclear and that should be revised by the authors. Additionally, reviewers may give suggestions to simplify the text and improve the communication impact of the manuscript by making it more accessible to non-scientific audiences. The reviewers may also suggest the addition in the article of the definitions of terms that are less common or unknown from the general public. The definitions appear in a glossary, on a left side margin in the final published version of the article, close to the place in the main text where the terms are used for the first time. Next, the report and suggestions of the high school reviewers are communicated to the authors to give them the possibility to make the necessary changes to the original text. The 
revised version by the authors is resubmitted to the high school reviewers for a final approval before publication. In a way, the high school students are introduced to a journal review process during the revision of the UALGORITMO manuscripts, and this activity has been perceived as a novel and enjoyable experience by them (Table 1 and Figure 2).

a
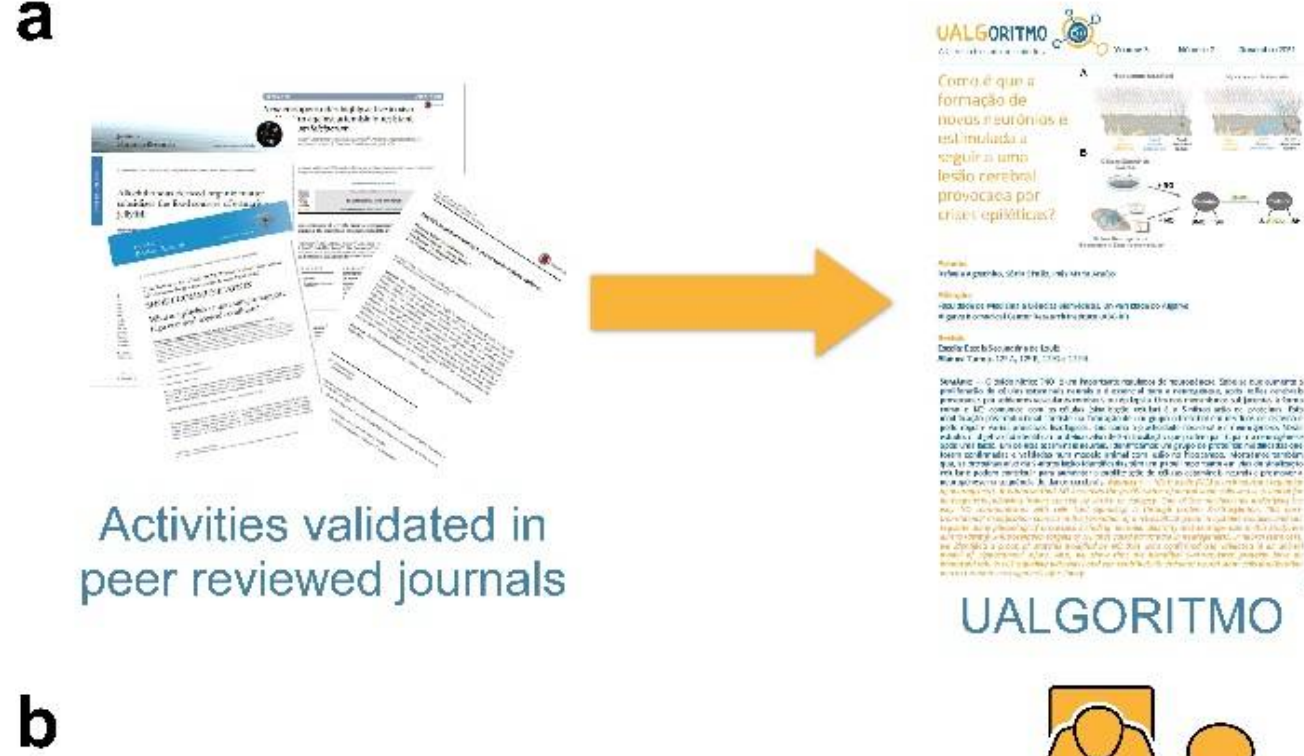

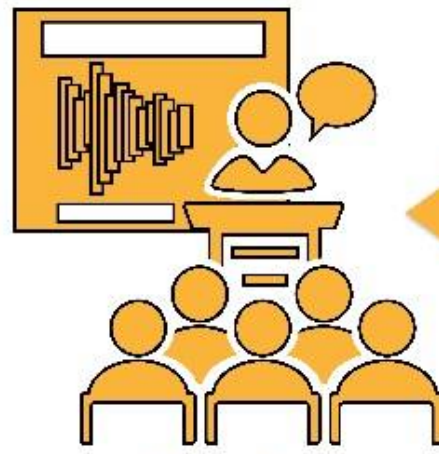

Scientists
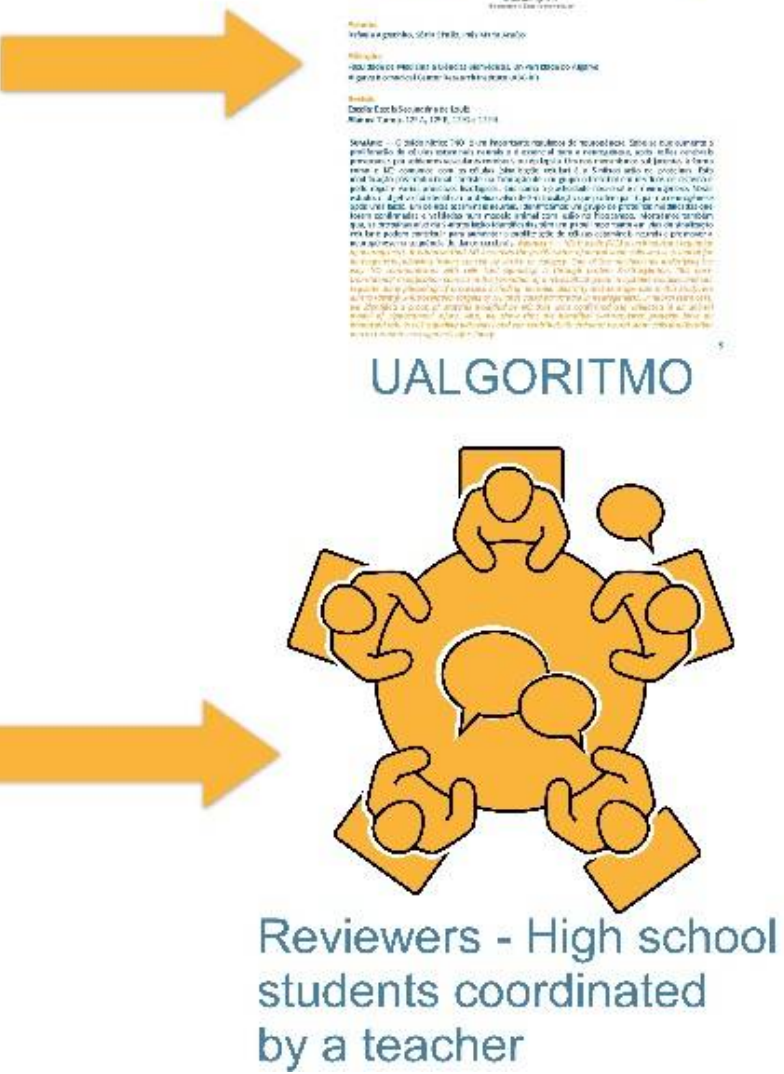

Figure 1. The UALGORITMO is an instrument for outreach activities to layman readers. (a) Articles published in peer reviewed journals (left) are the raw material for manuscripts submitted to the UALGORITMO (right); (b) The manuscripts from the authors (scientists), who often use a professional language difficult to understand by laymen, are reviewed for clarification of the text by secondary high school students under the coordination of a schoolteacher.

Table 1. Summary of the inquiry reports from high school students after the reviewing process ${ }^{1}$.

\begin{tabular}{llllll}
\hline & \multicolumn{3}{c}{ Grade (\%) } \\
\multicolumn{1}{c}{ Affirmations to be Graded from 1 to 5 } & $\mathbf{1}$ & $\mathbf{2}$ & $\mathbf{3}$ & $\mathbf{4}$ & $\mathbf{5}$ \\
\hline $\begin{array}{l}\text { 1-I enjoyed participating in the review process. 1 being equivalent } \\
\text { to "not really", and 5 to "it was an excellent experience" }\end{array}$ & 0 & 0 & 10 & 28 & 62 \\
$\begin{array}{l}\text { 2-I found the process very difficult. 1 being equivalent to "not } \\
\text { really", and 5 to "extremely complicated!" }\end{array}$ & 31 & 41 & 24 & 3 & 0 \\
\hline
\end{tabular}


Table 1. Cont.

\begin{tabular}{|c|c|c|c|c|c|}
\hline \multirow[b]{2}{*}{ Affirmations to be Graded from 1 to 5} & \multicolumn{5}{|c|}{ Grade (\%) } \\
\hline & 1 & 2 & 3 & 4 & 5 \\
\hline $\begin{array}{l}\text { 3-If there are more opportunities to participate in this type of } \\
\text { reviews, I want to participate. } 1 \text { being equivalent to "not really", and } \\
5 \text { to "for sure" }\end{array}$ & 0 & 10 & 7 & 28 & 55 \\
\hline $\begin{array}{l}4 \text {-The original text of the manuscript was clear and well written. } \\
1 \text { being equivalent to "not clear", and } 5 \text { to "very clear" }\end{array}$ & 0 & 21 & 17 & 48 & 14 \\
\hline $\begin{array}{l}\text { 5-The scientific activity of the article is clearly exposed, and I } \\
\text { understood everything. } 1 \text { being equivalent to "I didn't understand } \\
\text { anything", and } 5 \text { to "very clear" }\end{array}$ & 3 & 14 & 17 & 45 & 21 \\
\hline $\begin{array}{l}\text { 6-I liked the work presented. } 1 \text { being equivalent to "I didn't like it", } \\
\text { and } 5 \text { to "I loved it, it was super cool". }\end{array}$ & 0 & 3 & 14 & 38 & 45 \\
\hline 7-I learned a lot from reading the communication I reviewed. & & & & & \\
\hline $\begin{array}{l}1 \text { being equivalent to "I already knew all about that", and } 5 \text { to "I had } \\
\text { no idea about these things" }\end{array}$ & 0 & 10 & 31 & 34 & 24 \\
\hline $\begin{array}{l}\text { 8-In my opinion, the topic of the communication will interest many } \\
\text { secondary high school students and many other people who are not } \\
\text { scientists. } 1 \text { being equivalent to "I don't think so", and } 5 \text { to "yes, } \\
\text { without a doubt" }\end{array}$ & 0 & 7 & 21 & 48 & 24 \\
\hline $\begin{array}{l}\text { 9-After reading the communication I reviewed, I wanted to know } \\
\text { more about the topic. } 1 \text { being "I wasn't very interested", and } 5 \text { being } \\
\text { "I thought it was fantastic and I'm curious to see where this will end } \\
\text { up in the future" }\end{array}$ & 0 & 21 & 10 & 38 & 31 \\
\hline $\begin{array}{l}\text { 10-After reading the communication I reviewed, I felt like directing } \\
\text { my future studies in that direction. } 1 \text { being equivalent to "no, it's not } \\
\text { for me", and } 5 \text { to "studying and/or working in this area would } \\
\text { be fantastic" }\end{array}$ & 21 & 14 & 45 & 14 & 7 \\
\hline $\begin{array}{l}\text { 11-After reading the communication I reviewed, I wanted to know } \\
\text { more about the research activities of the University of Algarve. }\end{array}$ & & & & & \\
\hline $\begin{array}{l}1 \text { being equivalent to "no, it's not for me", and } 5 \text { to "yes I'm curious } \\
\text { to know about the other things that are done at the University } \\
\text { of Algarve" }\end{array}$ & 3 & 3 & 28 & 41 & 24 \\
\hline $\begin{array}{l}\text { 12-After reading the communication that was revised, I wanted to } \\
\text { know more about the educational training at the University of } \\
\text { Algarve. } 1 \text { being equivalent to "no, I'm interested", and } 5 \text { to "yes I } \\
\text { want to know more" }\end{array}$ & 3 & 24 & 31 & 21 & 21 \\
\hline
\end{tabular}

A small description and a picture of the reviewers are presented at the end of each article, as an acknowledgment for their valuable contribution to the revision of the manuscripts. The articles published in the UALGORITMO also contain a small biography of each author, and links to the websites of the research centers to which they belong, and links to the courses in which they teach at the University. To strengthen the outreach potential of the UALGORITMO, a website (https:/ / ualgoritmo.wixsite.com/website, accessed on 15 December 2021) has been created to present all the articles published with the information about the authors and the reviewers, and direct website links to the secondary high schools which have participated in the revision and the Ciência Viva Center of the Algarve, which has largely contributed to the first contacts made with secondary high schools and for the launch of the UALGORITMO project. 


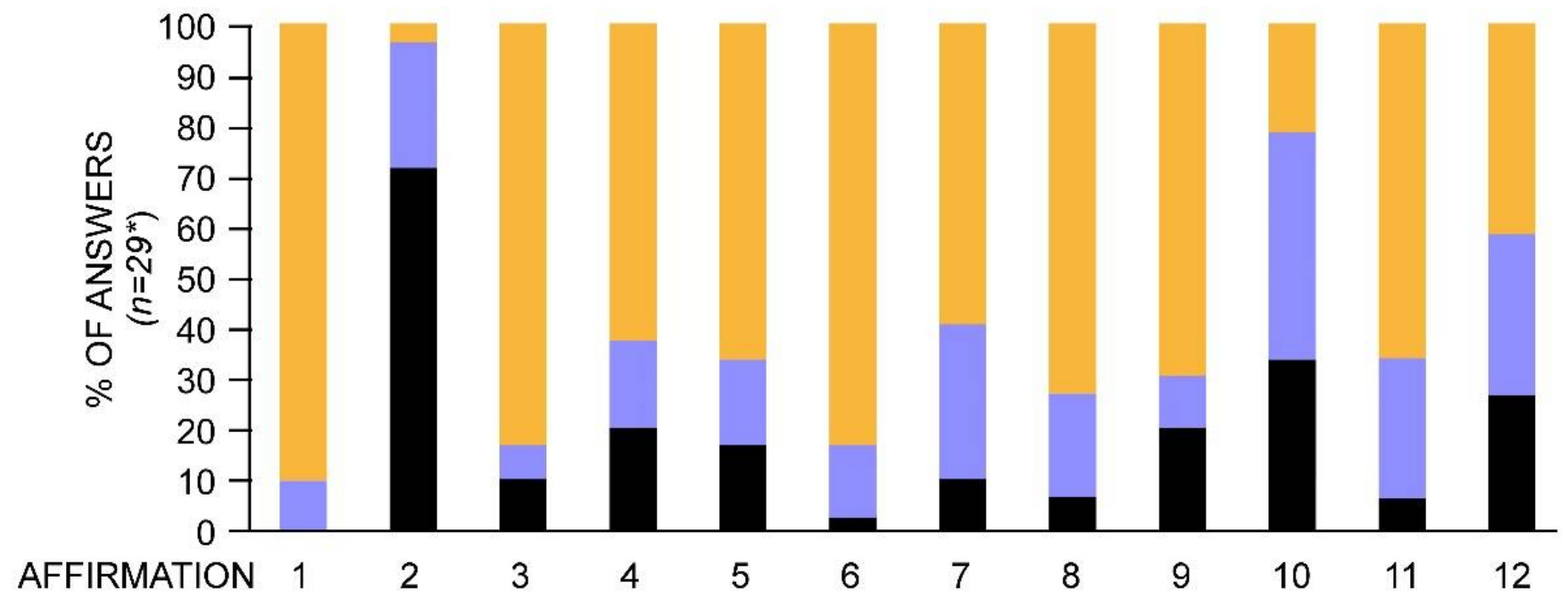

(A)

\section{A1. I liked to review}

Not really
It was OK
I enjoyed it

\section{A6. I liked} the topic

Not really
It was OK
I loved it
A2. It was a difficult process

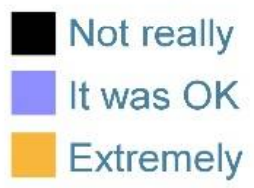

\section{A7. I learnt} a lot

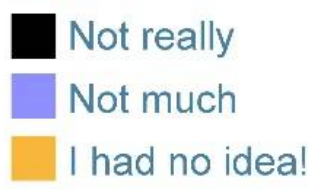

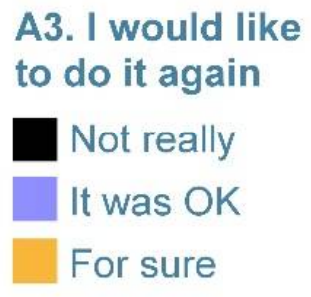

A3. I would like

A4. The text was well written

\section{A5. The science} was well exposed

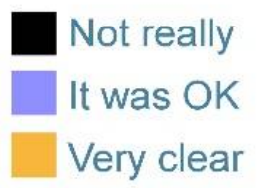

A8. The topic will interest

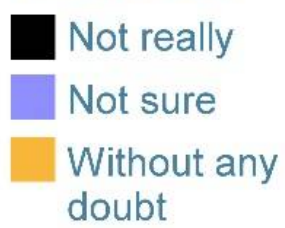

A9. I would like to A10. I would like to know more about it study this topic

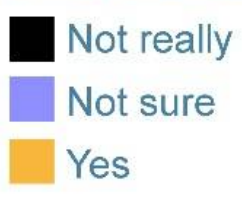

No

Not sure

It would be great

\section{A11. I would like to know more about the research at the University of Algarve}

A12. I would like o know more about the

Not really educational training at the University of Algarve

Kind of

Yes

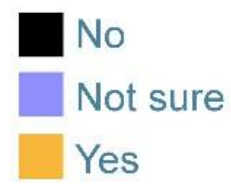

Figure 2. Graphical representation of the results from the inquiry after the review process. The results presented in Table 1 have been re-organized in such a way that answers 1 and 2 in one hand, and the answers 4 and 5 to in the other hand, which reflect nuances of the same answer were combined $\left.{ }^{*}\right)$, are represented by black and orange histograms, respectively. The neutral answer 3 is indicated by blue histograms. The histograms represent the percentage (\%) of answers. The summary of each affirmation and answers (A1 to A12) from the inquiry are presented below the graph.

\section{The UALGORITMO, Designed to Maximize the Outreach}

We believe that the reviewing process and the publication of the UALGORITMO maximizes the interaction between the University and all communities. Indeed, the first step of the outreach is the active and in-depth involvement of the high school students in the reviewing process, which implies understanding the work performed at the University of Algarve. The choice for the collaboration with secondary high school students, of the 10th to 12 th year grade for the reviewing process was made 
because these students have sufficient scientific culture to understand the message of the manuscript and to provide a real input in the improvement and the clarification of the text for a larger audience. Of interest for the University, these students are only few years away, or months even, from leaving high school and make a choice for the next step towards their future education and professional activities. Surprisingly, many students who participated in the review process were unaware of the many courses and training provided by the University of Algarve, and they were also delighted to discover the research areas undertaken at the University during the revision process (Table 1 and Figure 2). Thus, the collaboration in the revision of the manuscripts for the UALGORITMO is an opportunity to introduce the educational structure and activities of the University of Algarve to these high school students, and perhaps provide them with paths that they did not envision before being in contact with the scientific activities and courses of the University of Algarve.

In a second phase, we believe that the students will be inclined to announce their contribution to the revision of the UALGORITMO manuscripts to family and friends, with a regain of interest in the divulgation, when the UALGORTMO is published online. This would propagate the outreach beyond the reviewers' circle, and perhaps motivate other readers to be in contact with the University's activities through the UALGORITMO. Although the UALGORITMO is freely accessible online by virtually anyone, printed versions of the journal are also sent to the teachers who participated in the reviewing process and to all libraries of the secondary high schools of the Algarve, which we believe will constitute another level of dissemination of the University's activities.

We have also encouraged the participation of Master's or Doctoral students from research groups, in writing the communications for the UALGORITMO, even if they were not authors of the original peer reviewed article. In addition to the authorship in the UALGORITMO publication, we expect that these University students will find in this process a way to train their writing skills, and to be incentivized for future scientific outreach actions. Moreover, the involvement of the research students will certainly alleviate the writing task of the senior author by reducing the time spent in the preparation of the manuscript, and this liberates Senior authors for the development of other activities. Of course, we also believe that these students will communicate their participation in the publication to friends and family, and even mention this activity in their curriculum vitae, which may be considered as a form of outreach, particularly if the reader of the curriculum will have the curiosity to discover the UALGORITMO. Additionally, the Professors at the University may also recommend the publications in the UALGORITMO to their pupils and junior students for an easy immersion in the research thematic. Of interest, the abstract written in English was introduced to give the opportunity to non-Portuguese readers to learn about the research topic addressed by the authors, and to find the original peerreviewed article using the DOI presented in the reference section. This, in a way, provides another layer of dissemination of the original scientific report.

Finally, the launch of each new edition of the UALGORITMO is announced to the researchers and students at the University and to secondary high schools, and has taken place during meaningful events, such as the meeting of the Advisory Board for University of Algarve Training Offer, which has the strategic objective to bring the Algarve Academy closer to regional schools. This advisory board is constituted by representatives of the Councils of the Algarve, the General Direction of Schools and the Employment and the Vocational Training Institute. Thus, the launch of the UALGORITMO has also repercussions through the academic and regional communities present at this event.

Overall, the strategy surrounding the preparation, edition, launch, as well as the accessibility of the UALGORITMO contributes to maximize the impact of this journal to fulfil the scientific outreach expected. 


\section{The Reviewing Process of the Manuscripts and the High School Educational Mission}

The rules for the revision of the UALGORITMO manuscripts were purposely left simple to provide a maximal autonomy to the reviewers. In essence the only rule is that the reviewers have to be students of the 10th, 11th, or 12th year grade and supervised by a teacher. Consequently, reviewing groups were composed, organized, and managed in very different ways according to schools and supervisors. Curiously, some reviewing groups were constituted by only one or two students, while others gathered a larger number of students, some of which were composed by up to three different classrooms engaged in different educational fields, such Biology/Geology and Portuguese, or Languages/Humanities and Biology/Geology. An interesting heterogeneous group was formed with students from different year grades (11th and 12th), as well as different educational fields and classrooms, such as Languages/Humanities, Sciences/Technology, and Socioeconomical Sciences. Some teachers have opted for the revision of manuscripts related to the fields that they teach, while others have not directed their choice to any particular field. This heterogeneity in the composition of the group of reviewers may explain the fact that some students are not inclined to continue their educational training in paths related to the topics that they have reviewed in the manuscript, although they enjoyed reading about the topic (Table 1 and Figure 2). Indeed, it is unlikely for a student engaged in Languages/Humanities to wish to continue in Sciences, for example.

Thus, multiple revision strategies were implemented by the reviewers, but we will briefly exemplify the modus operandi adopted by two groups. The first example comes from a reviewing group composed of a unique classroom, in which the teacher first instructed all students to the reviewing process. Next, each student received a copy of the manuscript for an individual reading to identify the central idea/message of the article. Then, all students together reviewed the article and discussed the concepts and definitions, explored the scientific question, highlighted the significant passages and information that complemented the central idea. In addition, the students collaborated to search for related articles and check whether these articles described data in agreement with the message presented in the manuscript under review. During the reviewing process, the students also learnt the bases for the construction of argumentative texts, and finally they reported to the authors the changes necessary in the text and whether relevant aspects were missing in the manuscript. The second example of the reviewing strategy involves two classrooms, Science/Technology and Languages/Humanities. Here, the revision process started with Science/Technology class, which was divided into several groups for independent analysis of the manuscript. After the initial analysis, each group presented a proposal for changes in the texts, definitions to be added to the glossary, and novel illustrations. All proposals from each group were then analyzed by the entire class to identify all unknown concepts and expressions. Next, a structured revision proposal combining all changes suggested, was communicated to the second group of reviewers composed of the Languages/Humanities students. This second group of reviewers proceeded the revision as described for the first group and sent their own comments back to the first group for a final agreement on changes to be proposed to the authors.

The program of the XXI Portuguese Constitutional Government in the law decree 55/2018 (https:/ / dre.pt/dre/detalhe/decreto-lei/55-2018-115652962, accessed on 15 December 2021) and in the directives Profile of Students Leaving Mandatory Schooling (in Portuguese Perfil dos Alunos à Saída da Escolaridade Obrigatória, termed PASEO hereafter, approved by the dispatch 6478/2017, https://dre.pt/dre/detalhe/despacho/6478-201 7-107752620, accessed on 15 December 2021), has established the priority to implement student-centered educational policies in secondary high schools, by creating conditions for a balance between knowledge, understanding, creativity/originality, and a critical/creative attitude. The objective is for high schools to prepare students to develop skills that will allow them to understand and integrate new knowledge, to communicate efficiently and to solve complex problems that they may face due to globalization and accelerating technolog- 
ical developments. Undoubtedly, the diverse methodologies adopted by the reviewers for the revision of manuscripts to be published in UALGORITMO have allowed the students to develop practically all the skills listed in PASEO.

In addition, through its articles, the UALGORITMO may also be envisioned as an instrument to facilitate the very important and continuous actualization of the scientific knowledge and competencies that schoolteachers have to renew and acquire in order to efficiently transmit to their students the scientific literacy and skills needed to face ongoing and future societal challenges [9].

\section{Discussion}

The UALGORITMO is a free digital journal dedicated to the outreach of scientific, technologic, and artistic activities of the University of Algarve for the lay public. For a maximum impact of outreach by the UALGORITMO, the texts of the manuscripts submitted by the authors are tendentially written with simple day-to-day Portuguese language and revised by students at secondary high schools for further clarification. To simplify both the writing and the revision processes in the UALGORITMO project, we have opted for short manuscripts that summarize a main publication of the authors in a peer reviewed journal. Indeed, to summarize a published work is much easier and less time consuming for the authors than to write an original publication, and it is well reported that time is an issue for scientists to engage in outreach activities [8]. In addition, since the reviewers do not have to validate any science exposed in the manuscript, their task is easier, and they can concentrate their effort on the simplification of the text. In this respect, the project UALGORITMO is in line with other international science communication initiatives and outreach for society, such as "Atlas of Science" (https://atlasofscience.org/, accessed on 15 December 2021) and "Frontiers for Young Minds" (https:/ / kids.frontiersin.org/, accessed on 15 December 2021), in which the articles published are written by scientists. However, in the "Atlas of Science" published layman's summary articles are not reviewed, and in "Frontiers for Young Minds" the manuscripts are revised by children and young people. The participation of the researchers of the University of Algarve and high school students to the preparation and revisions of the manuscripts to the UALGORITMO has been very enthusiastic and dynamic and has already allowed the publication of four volumes since its launch in October 2019. The UALGORITMO is freely available online to the general public on several websites either dedicated to the UALGORITMO project itself and at the University website, or on social networking sites for scientists, such as ResearchGate, dedicated to the community and researchers and students interested in science. Although the published articles have been read and downloaded thousands of times on the various websites where they are available, there is a lack of an instrument that can precisely determine their impact on the general public and students interested by science. In the future, to expand further the outreach, it would be interesting to develop complementary summaries of the work presented by the authors in short audio or video supports that would be available at the UALGORITMO website and other social media sharing platforms.

Apart from fulfilling the purpose of disseminating science and arts generated at the University of Algarve, the UALGORITMO contributes to the exposition and discovery of the University from a larger population. This is a very positive and important aspect since the University of Algarve was only founded a little over 40 years and has not yet reached the prestige of other Universities in Portugal, some of which have multiple centuries of existence. Furthermore, the University of Algarve is located in the far south of Portugal, far from the strong economic and cultural national cities that exert an attraction for many people, including students of secondary education of the Algarve who consider these places as their next path for future higher education. However, these students often disregard the University of Algarve because they are simply unaware of the activities developed at this University. The results obtained during this relatively short time of interaction with the secondary high schools for the purpose of revision of the manuscripts submitted to the UALGORITMO, clearly reveals this fact through the answers to the enquiries that 
the students have given. Interestingly, the results of these enquiries also indicate that a substantial proportion of these students have interest in discovering more about the University of Algarve. This is another very positive aspect of the UALGORITMO as a mean for outreach, developed in close collaboration with high school students, because it encourages a genuine curiosity for other activities developed at the University of Algarve, and it facilitates the access to websites containing all the information about research and teaching. In the future, it would be of interest to evaluate whether the UALGORITMO had an impact in the high school students' community for their ingression at the University of Algarve. Similar initiatives to the UALGORITMO could be adopted by other national or foreign universities that are outside the main educational scope to promote their visibility both at a local and national level.

Finally, we believe that the UALGORITMO also serves the high school education objectives delineated by the Portuguese educational system, since the reviewing processes of the manuscripts for the UALGORITMO involve methods and techniques that support students in building a genuine scientific, technical, and technological knowledge and culture, through the interpretation and communication of information and critical and creative thinking, which additionally contribute to values such as citizenship and engagement, curiosity, reflection, and innovation. Moreover, the UALGORITMO project is also very pertinent because students, acting as reviewers of articles, become more aware of how science is advanced and transmitted, and may be inspired to be involved in research in their future professional careers. On the other hand, they actively contribute to the dissemination science and its understanding by the public, by turning the message of a scientific article into an article that simplifies the scientific language, in a language more accessible to everyone, which allows for the promotion of scientific literacy in the community in general. This aspect is particularly important in Portugal, since studies carried out on the scientific literacy of the Portuguese population showed that decades ago the scientific knowledge of the Portuguese used to be lower than the average of the populations of other European countries. However, in recent years Portugal has been one of the few countries of the Organisation for Economic Co-operation and Development (OCDE) with clear improvements in youngsters' scientific literacy, which results from a Portuguese policy to improve teachers' qualification with a reinforcement of their scientific education programmes and implementation of lifelong training options for their career development and progression, and from an increasing effort of outreach engagement by scientific communities [10-13].

Author Contributions: Conceptualization, J.B.; writing-original draft preparation, J.B., S.F. and C.A.R.; writing-review and editing, J.B., S.F., C.A.R., F.d.R.C. and S.N.d.J.; project administration, J.B. All authors have read and agreed to the published version of the manuscript.

Funding: This work was supported by Fundação para a Ciência e Tecnologia (FCT) and the Comissão de Coordenação e Desenvolvimento Regional do Algarve (CCDR Algarve) for the project ALG-010145-FEDER-28044 “VITAL”, PTDC/BTM-TEC/28044/2017.

Institutional Review Board Statement: Not applicable.

Informed Consent Statement: Not applicable.

Data Availability Statement: Not applicable.

Acknowledgments: This work is dedicated to the memory of Laura A. Bragança (12 May 2003-10 May 2019), who inspired the realization of the UALGORITMO, and to Mariana Isabel SLP Alves (9 July 1992-5 May 2008). We thank the authors of the articles published in the UALGORITMO, and the students of Secondary Education and their teachers for the reviewing process. Finally, we thank all members of the UALGORITMO Editorial Committee and Associate Editors, the staff of the Library of the University of Algarve with a special thanks to Salomé D'horta, and Cristina Viegas-Pires director of the Ciência Viva Center of the Algarve.

Conflicts of Interest: The authors declare no conflict of interest. 


\section{References}

1. Entradas, M.; Bauer, M.W.; O’Muircheartaigh, C.; Marcinkowski, F.; Okamura, A.; Pellegrini, G.; Besley, J.; Massarani, L.; Russo, P.; Dudo, A.; et al. Public communication by research institutes compared across countries and sciences: Building capacity for engagement or competing for visibility? PLOS ONE 2020, 15, e0235191.

2. McClure, M.B.; Hall, K.C.; Brooks, E.F.; Allen, C.T.; Lyle, K.S. A pedagogical approach to science outreach. PLoS Biol. 2020, 18, e3000650. [CrossRef] [PubMed]

3. Brownell, S.E.; Price, J.V.; Steinman, L. Science Communication to the General Public: Why We Need to Teach Undergraduate and Graduate Students this Skill as Part of Their Formal Scientific Training. J. Undergrad. Neurosci. Educ. 2013, 12, E6-E10. [PubMed]

4. Wilson, M.J.; Ramey, T.L.; Donaldson, M.; Germain, R.R.; Perkin, E.K. Communicating science: Sending the right message to the right audience. Facets 2016, 1, 127-137. [CrossRef]

5. Kappel, K.; Holmen, S.J. Why Science Communication, and Does It Work? A Taxonomy of Science Communication Aims and a Survey of the Empirical Evidence. Front. Commun. 2019, 4, 4. [CrossRef]

6. Weigold, M. Communicating Science: A Review of the Literature. Sci. Commun. 2001, 23, 164-193. [CrossRef]

7. Besley, J.C.; Dudo, A.; Yuan, S.; Lawrence, F. Understanding Scientists' Willingness to Engage. Sci. Commun. $2018,40,559-590$. [CrossRef]

8. Ecklund, E.H.; James, S.A.; Lincoln, A.E. How Academic Biologists and Physicists View Science Outreach. PLoS ONE 2012, 7, e36240.

9. Azevedo, M.-M.; Duarte, S. Continuous Enhancement of Science Teachers' Knowledge and Skills through Scientific Lecturing. Front. Public Health 2018, 6, 41. [CrossRef] [PubMed]

10. European Commission. European citizens' knowledge and attitudes towards science and technology. Spec. Eurobarometer 2021, $516,1-4$.

11. Cordeiro, A.M.R.; Alcoforado, L. Education and development. Méditerranée 2018, 130, 1-14. [CrossRef]

12. OECD. OECD Skills Strategy Diagnostic Report: Portugal 2015; OECD: Paris, France, 2015. [CrossRef]

13. OCDE. PISA 2012 Results in Focus What 15-Year-Olds Know and What They Can Do with What They Know; OCDE: Paris, France, 2012. Available online: https:/ / www.oecd.org/pisa/keyfindings/pisa-2012-results.htm (accessed on 15 December 2021). 